\title{
In situ science on Phobos with the Raman spectrometer for MMX (RAX): preliminary design and feasibility of Raman measurements
}

\author{
Yuichiro Cho ${ }^{1 *+} @$ , Ute Böttger ${ }^{2 \dagger}{ }^{\dagger}$, Fernando Rull ${ }^{3 \dagger}$, Heinz-Wilhelm Hübers ${ }^{2 \dagger}$, Tomàs Belenguer ${ }^{4}$, Anko Börner ${ }^{2}$, \\ Maximilian Buder ${ }^{2}$, Yuri Bunduki ${ }^{2}$, Enrico Dietz ${ }^{2}$, Till Hagelschuer ${ }^{2}$, Shingo Kameda ${ }^{5,9}$, Emanuel Kopp ${ }^{2}$, \\ Matthias Lieder², Guillermo Lopez-Reyes ${ }^{3}$, Andoni Gaizka Moral Inza ${ }^{4}$, Shoki Mori ${ }^{1}$, Jo Akino Ogura', \\ Carsten Paproth², Carlos Perez Canora ${ }^{4}$, Martin Pertenais ${ }^{2}$, Gisbert Peter ${ }^{2}$, Olga Prieto-Ballesteros ${ }^{6}$, \\ Steve Rockstein ${ }^{2}$, Selene Rodd-Routley², Pablo Rodriguez Perez ${ }^{4}$, Conor Ryan ${ }^{2}$, Pilar Santamaria ${ }^{4}$, \\ Thomas Säuberlich², Friedrich Schrandt ${ }^{2}$, Susanne Schröder ${ }^{2}$, Claudia Stangarone $^{7}$, Stephan Ulamec ${ }^{8}$, \\ Tomohiro Usui ${ }^{9}$, Iris Weber ${ }^{10}$, Karsten Westerdorff ${ }^{2}$ and Koki Yumoto ${ }^{1}$
}

\begin{abstract}
Mineralogy is the key to understanding the origin of Phobos and its position in the evolution of the Solar System. In situ Raman spectroscopy on Phobos is an important tool to achieve the scientific objectives of the Martian Moons eXploration (MMX) mission, and maximize the scientific merit of the sample return by characterizing the mineral composition and heterogeneity of the surface of Phobos. Conducting in situ Raman spectroscopy in the harsh environment of Phobos requires a very sensitive, compact, lightweight, and robust instrument that can be carried by the compact MMX rover. In this context, the Raman spectrometer for MMX (i.e., RAX) is currently under development via international collaboration between teams from Japan, Germany, and Spain. To demonstrate the capability of a compact Raman system such as RAX, we built an instrument that reproduces the optical performance of the flight model using commercial off-the-shelf parts. Using this performance model, we measured mineral samples relevant to Phobos and Mars, such as anhydrous silicates, carbonates, and hydrous minerals. Our measurements indicate that such minerals can be accurately identified using a RAX-like Raman spectrometer. We demonstrated a spectral resolution of approximately $10 \mathrm{~cm}^{-1}$, high enough to resolve the strongest olivine Raman bands at $\sim 820$ and $\sim 850 \mathrm{~cm}^{-1}$, with highly sensitive Raman peak measurements (e.g., signal-to-noise ratios up to 100). These results strongly suggest that the RAX instrument will be capable of determining the minerals expected on the surface of Phobos, adding valuable information to address the question of the moon's origin, heterogeneity, and circum-Mars material transport.
\end{abstract}

Keywords: Raman spectroscopy, Raman spectrometer for MMX (RAX), Phobos, Mineralogy, In situ analysis, Sample return, Martian Moons eXploration (MMX)

\footnotetext{
*Correspondence: cho@eps.s.u-tokyo.ac.jp

†Yuichiro Cho, Ute Böttger, Fernando Rull, Heinz-Wilhelm Hübers should

be regarded as joint first authors

${ }^{1}$ Department of Earth and Planetary Science, The University of Tokyo,

7-3-1 Hongo, Bunkyo, Tokyo 113-0033, Japan

Full list of author information is available at the end of the article
}

(c) The Author(s) 2021. Open Access This article is licensed under a Creative Commons Attribution 4.0 International License, which permits use, sharing, adaptation, distribution and reproduction in any medium or format, as long as you give appropriate credit to the original author(s) and the source, provide a link to the Creative Commons licence, and indicate if changes were made. The images or other third party material in this article are included in the article's Creative Commons licence, unless indicated otherwise in a credit line to the material. If material is not included in the article's Creative Commons licence and your intended use is not permitted by statutory regulation or exceeds the permitted use, you will need to obtain permission directly from the copyright holder. To view a copy of this licence, visit http://creativecommons.org/licenses/by/4.0/. 


\section{Graphical Abstract}
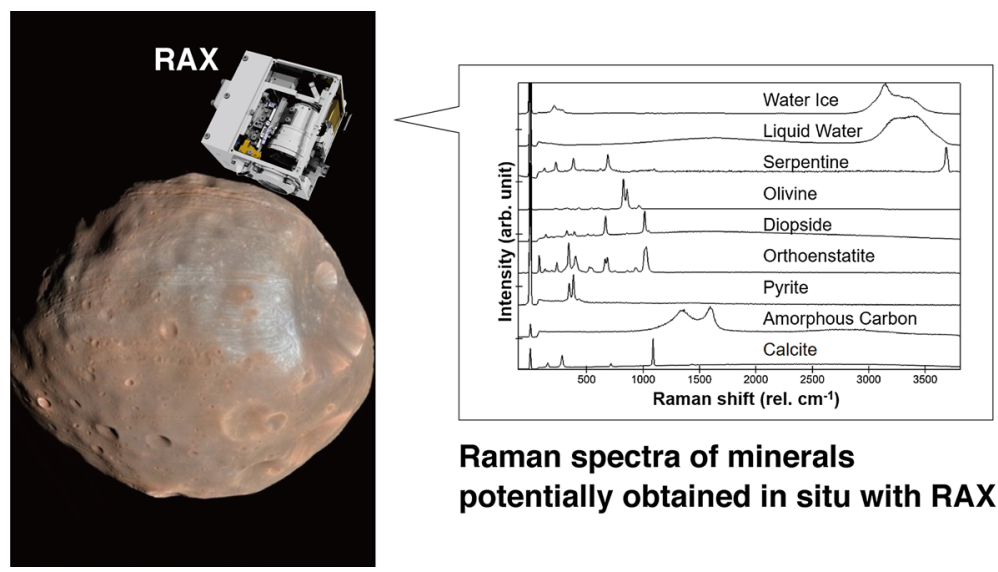

\section{Origin of Phobos \\ CDaptured asteroid? Giant impact?}

\section{Raman spectra of minerals potentially obtained in situ with RAX}

\section{Introduction}

The evolution of the Solar System is a fundamental topic of research. Studying the composition of the planetary bodies provides insights into their possible origin and helps to understand the geochemical and thermal processes experienced by the body.

Different spectroscopic techniques are generally used to obtain the composition of the planetary bodies. Before space flight was realized, only Earth-based observations were available for investigation. With the advent of space missions, spacecrafts fitted with spectrometers and cameras are used to capture images and spectra in the ultraviolet (UV), visible, and infrared spectral ranges. By comparing these spectra with those obtained from similar studies on Earth, it is possible to derive the surface composition on a macroscale spatial resolution. In situ exploration and samples collected from these bodies provide more information, particularly on a microscale spatial resolution. In situ measurements provide an initial overview of the general composition of the investigated target at individual surface points. Detailed analyses of the returned samples with the geologic context provide a much deeper understanding of the surface processes of the investigated body. The combination of such information allows us to visualize the processes that the body may have experienced throughout its lifetime, and helps in verifying the existing hypotheses or establishing alternative ones for its evolution and thus, of the Solar System. Numerous examples exist for all the approaches, such as the Japan Aerospace Exploration Agency (JAXA)

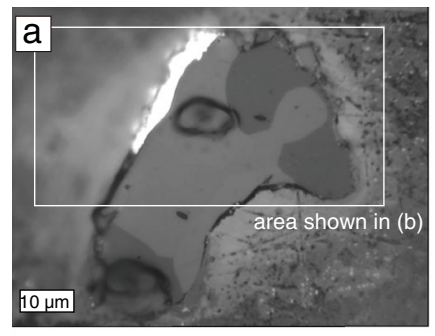

$\mathrm{b}$

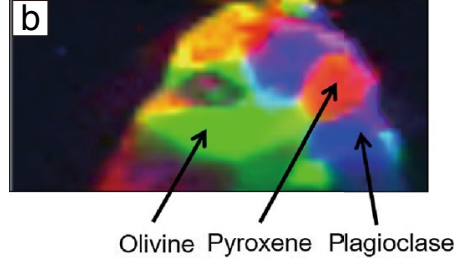

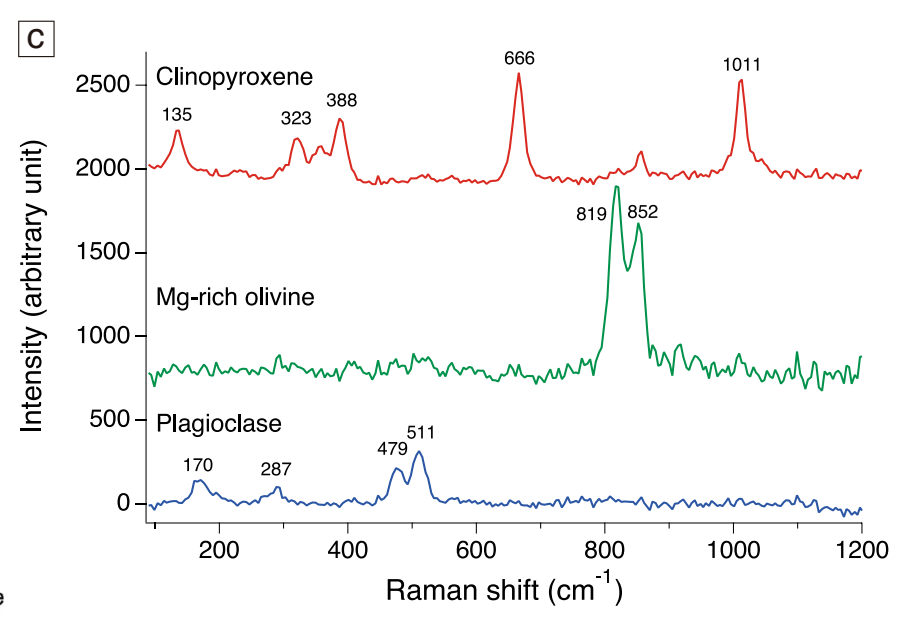

Fig. 1 a Microscopic image of a cut, sputtered, and polished Hayabusa Particle RA-QD02-0051 embedded in epoxy. b Color composite of mineral composition derived from Raman spectral imaging at DLR Berlin. c Raman spectra of typical minerals found on this particle. The colors of the spectra correspond to the colors of the Raman spectral image. Top—clinopyroxene; middle-Mg-rich olivine; bottom—plagioclase (Böttger et al. 2013) 
Table 1 Origin hypotheses for Phobos and the predicted mineral abundances (Murchie et al. 2014)

\begin{tabular}{ll}
\hline Hypotheses for origin & Mineral abundances \\
\hline $\begin{array}{ll}\text { 1. Capture of organic- and water-rich outer solar system body } \\
\text { 2. Capture of organic- and water-poor outer solar system body }\end{array}$ & $\begin{array}{l}\text { Abundant phyllosilicates; carbonates and organic phases; anhydrous silicate phases } \\
\text { rare } \\
\text { graphite? }\end{array}$ \\
$\begin{array}{ll}\text { 3. Capture of inner solar system body } \\
\text { Low carbonates, phyllosilicates; pyroxene, olivine probably in range of known mete- } \\
\text { orites }\end{array}$ & $\begin{array}{l}\text { Anhydrous silicates with Fe, Mg of bulk Mars; low abundance of C-bearing phases } \\
\text { Evolved, basaltic mineralogy consistent with many datasets for Mars }\end{array}$
\end{tabular}

Hayabusa mission. In this mission, the asteroid Itokawa was first studied using remote instrumentation (Krot 2011). The samples collected from the surface of the asteroid were brought back to Earth, where they were studied in laboratories using highly sophisticated methods, such as backscattered electron microscopy (Nakamura et al. 2011), neutron activation (Ebihara et al. 2011), synchrotron radiation X-ray tomographic microscopy (SRXTM) (Meier et al. 2013), isotopic measurements and mass spectroscopy (Yurimoto et al. 2011; Nagao et al. 2011; Busemann et al. 2013), and Raman microscopy (Böttger et al. 2013) (Fig. 1).

Mineralogy is a key discipline for such studies since it helps to correlate the occurrence and abundance of different minerals to the geochemical, thermal, or radiation processes that led to their formation. Thus, such techniques to derive the in situ mineralogical composition are of great interest. Raman spectroscopy is an appropriate method for this purpose. It is a nondestructive fingerprinting method that does not require sample preparation, and can be applied in field as well as in laboratories. The technique is used in investigation of various materials, including minerals, organic and biological matter, liquids, gases, ice, and brine.

Thus, the development of Raman spectrometers for in situ exploration is receiving increased attention in space research (e.g., Rull et al. 2017; Weber et al. 2017, 2018). With SuperCam on the Mars 2020 rover mission (Wiens et al. 2021) and the Raman Laser Spectrometer (RLS) on the ExoMars 2022 mission (Rull et al. 2017), Raman instruments will be used for the first time on the surface of Mars for mineralogical studies and to search for signatures of past or present life. The SuperCam is a stand-off, time-gated Raman spectrometer, using a 532$\mathrm{nm}$ pulsed laser, while the RLS is a confocal microscopelike Raman spectrometer, using a 532-nm continuous wave $(\mathrm{CW})$ laser. Both instruments are designed to work in Martian environments. In contrast, the rover developed for JAXA's Martian Moons eXploration (MMX) mission (Kawakatsu et al. 2019) will carry a compact
Raman spectrometer for MMX (the RAX), to investigate the surface of Phobos (Ulamec et al. 2019; Michel et al. 2021).

In this study, we focus on the presentation of Raman spectroscopy on Phobos. We discuss how Raman spectroscopy can help in understanding the origin of Phobos, adding valuable information on the evolution of the Solar System. First, we describe the main scientific questions related to Phobos. Second, the current instrument design to achieve the defined goals is illustrated, followed by our measurements on several mineral samples relevant to Phobos and Mars to demonstrate the capability of RAX.

\section{Exploration of Phobos and the RAX instrument} In situ science on Phobos

Phobos is one of the two moons of Mars. It is orbiting Mars at a distance of approximately $6000 \mathrm{~km}$ in $7.65 \mathrm{~h}$. One Phobos-day is equal to its orbital period owing to tidal locking. The second moon, Deimos is more than 23,460 km above Mars' surface and completes an orbit in $30.3 \mathrm{~h}$. Both moons present similar albedo and spectral behavior, but their origin is still unknown. Several models for their origin have already been discussed in detail (e.g., Pieters et al. 2014; Usui et al. 2020; Michel et al. 2021). Here, we focus on how Raman spectroscopy can contribute in addressing the question of the origin of Phobos.

To address this issue, we need to briefly review the five most relevant hypotheses regarding the origin of Phobos, each of which is supported by a selection of minerals that are expected to be present on Phobos. Murchie et al. (2014) and Usui et al. (2020) described the expected mineralogy and geochemistry of Phobos with respect to its origin hypotheses.

According to these hypotheses, the moons were formed due to capture or in situ processes. The "capture" hypothesis proposes formation of the moons by the capture of (1) an organic- and water-rich outer Solar System body, (2) an organic- and water-poor outer Solar System body, or (3) an inner Solar System body. The "in situ formation" hypothesis proposes either (4) co-formation with 
Mars or (5) formation from the ejecta after an impact of a large body onto Mars. Each of these hypotheses predicts a specific composition, along with elemental and mineral abundances (Table 1). The currently available reflectance spectra measured remotely are not adequately conclusive to determine mineral abundances because of the lack of features attributable to specific minerals. The low albedo of Phobos can be explained by either a carbonaceous origin or by darkening through strong space weathering (e.g., Shirley and Glotch 2018 and references therein), with the corresponding mineralogy supporting the different processes. The spectra of the "red" and "blue" areas on Phobos best match those of the D-type and T-type asteroids, respectively (Rosenblatt 2011). The striking "blue/red" contrast could be caused by compositional or spatial variations in its physical surface properties (Rosenblatt 2011; Ballouz et al. 2019). Understanding the nature of color differences and their relationship to mineralogy is important to resolve this issue. Endogenous materials, such as fragments of Mars ejecta (Ramsley and Head 2013; Hyodo et al. 2019) and projectiles that hit Phobos should also be distinguished from the original Phobos material. Therefore, a measurement technique such as Raman spectroscopy, capable of identifying different minerals, will be of great benefit.

\section{Science with RAX}

In Fig. 2, the Raman spectra of some representative minerals predicted in the origin hypotheses of Phobos are shown, with distinguishable spectra and specific fingerprint characters.

In addition to mineral identification with only optical access to the sample, no sample preparation is necessary, which makes Raman spectroscopy a suitable technique for space exploration. Regardless of certain limitations, such as spectrally superimposing broadband fluorescence and low Raman scattering efficiency of certain materials such as hematite, it is an appropriate method for the initial examination of an unknown surface.

To characterize the mineralogy of Phobos, RAX was developed in collaboration with Japan, Spain, and Germany, to participate in the Japanese MMX Mission, as part of the payload on the Deutsches Zentrum für Luftund Raumfahrt (DLR)- Centre national d'études spatiales (CNES) Rover that will land on Phobos' surface during this mission (Hagelschuer et al. 2019). The MMX mission (Kawakatsu et al. 2019) and the rover are described in more detail in other papers (Michel et al. 2021; Kuramoto et al. 2021).

The objectives derived for RAX are according to the scientific goals formulated for the MMX mission (Kuramoto et al. 2021). First, RAX shall investigate the surface mineralogy of Phobos by measuring its Raman spectra

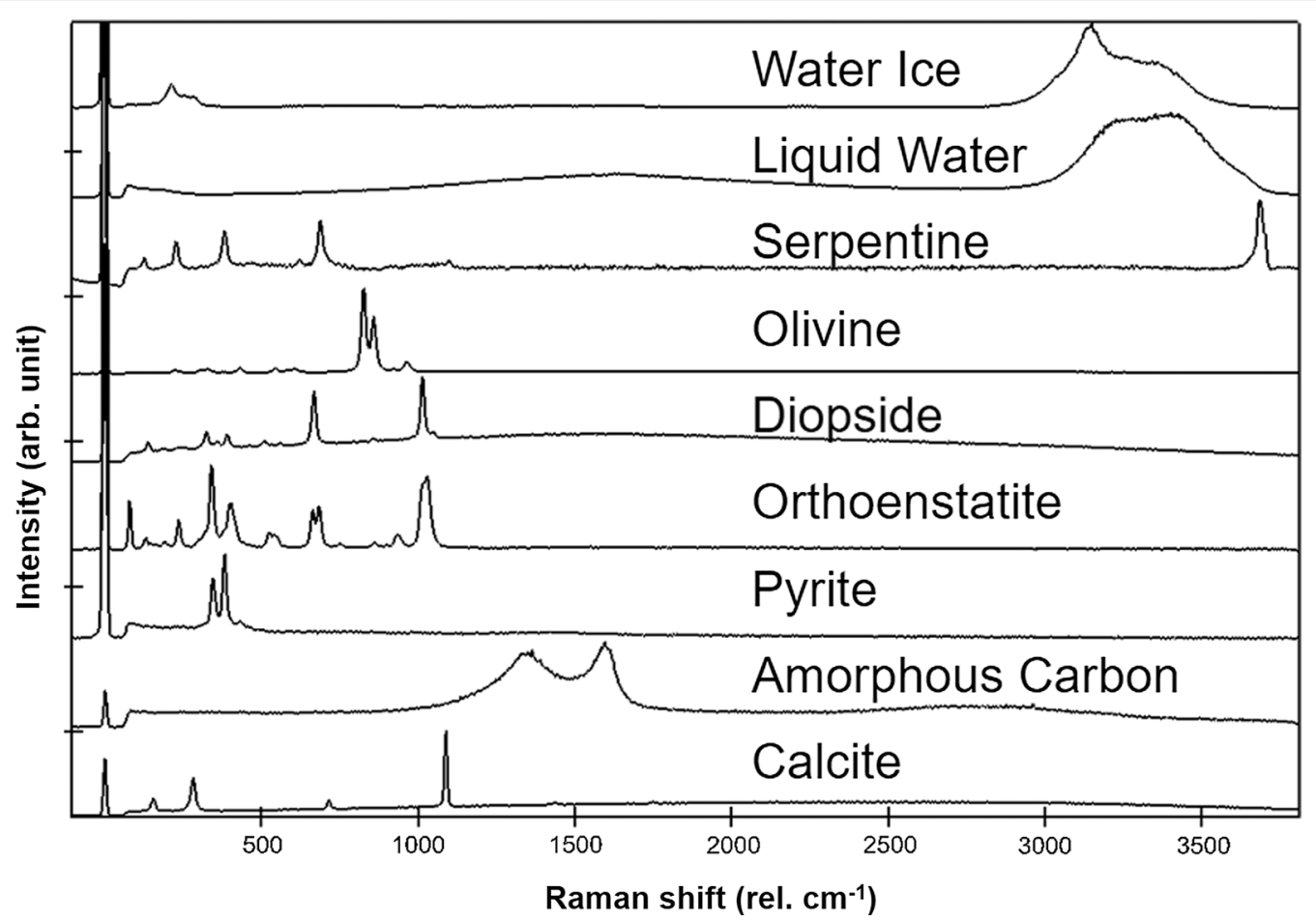

Fig. 2 Raman spectra of some representative minerals predicted for the origin hypotheses of Phobos 
Raman Spectrometer for MMX (RAX)

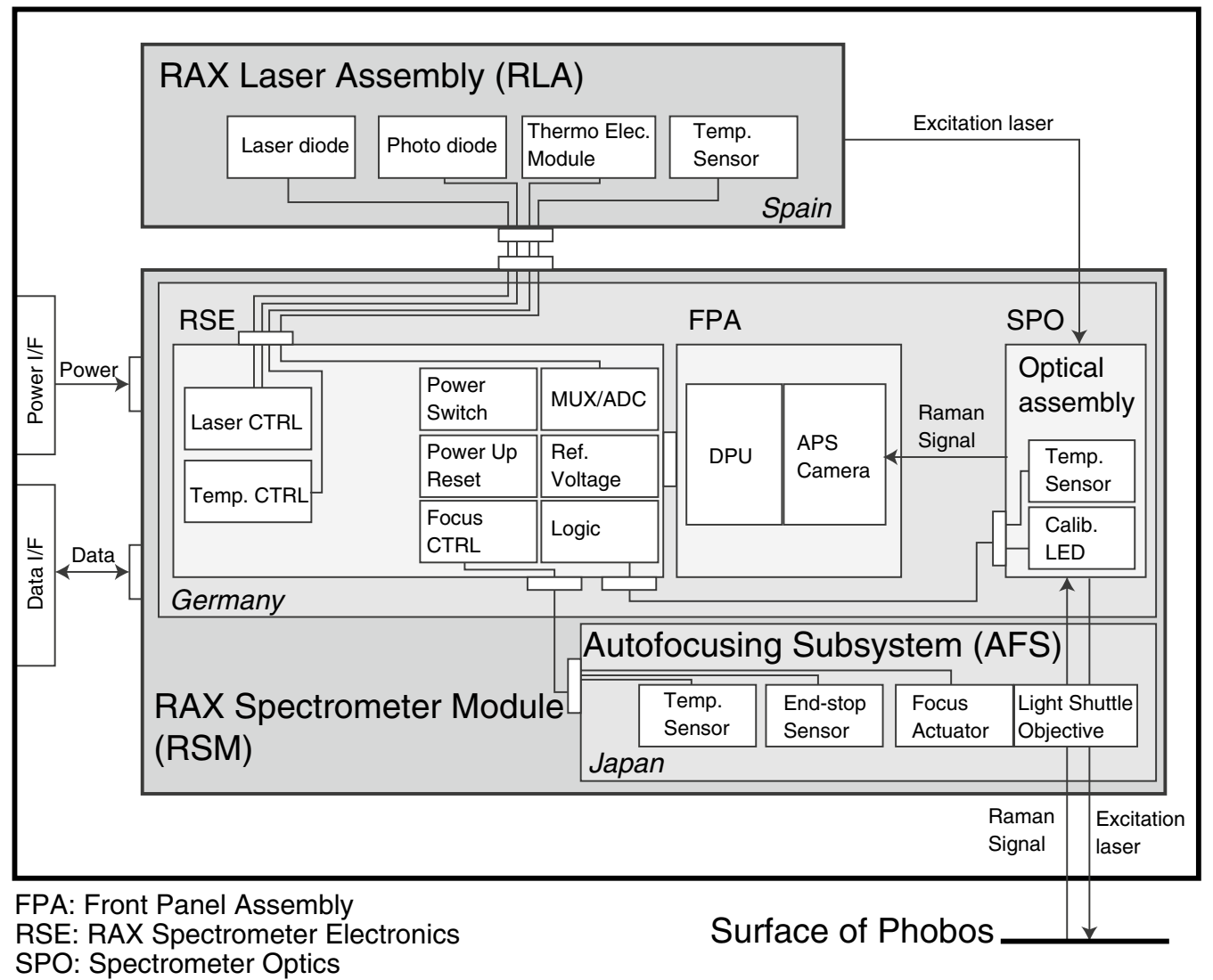

Fig. 3 Block diagram of the RAX instrument. RSM, RLA, and AFS are developed by Germany, Spain, and Japan, respectively

and identifying the mineral composition based on available databases. The rover's movement on the surface of Phobos allows measurement of the Raman spectra at different locations to study surface heterogeneity. This aspect can help characterize a possible landing site and select samples to carry back to Earth. The obtained data can also be compared to those from the surface of Mars to check the "in situ formation" origin hypothesis. The data obtained from the returned samples would confirm the results of RAX. Comparing the data obtained from the RAX and the returned samples will help to ensure representativeness of the returned samples, thus maximizing the scientific value of this mission.

The RAX measurements will be performed during the Phobos nighttime or in the shadow of the rover to avoid ambient light, which could be stronger than the Raman signals by orders of magnitude. Coarse laser focusing is achieved by raising or lowering the main body of the rover carrying the RAX instrument. Images of the RAX footprint, which provides the geological context of the measured samples, including their albedo, texture, and grain size, will be captured by the WheelCam (Michel et al. 2021). Measuring the Rover wheel tracks might provide information on original and unexposed regolith, which should be free from space weathering. Using an LED for surface illumination, RAX can also obtain reflectance spectra in a wavelength range of approximately $532-680 \mathrm{~nm}$ to evaluate the albedo and color of the surface material.

\section{Design of RAX}

Despite its high scientific value, conducting Raman spectroscopy on Phobos to fulfill the scientific objectives is a technical challenge. The instrument must endure the extreme diurnal environment of Phobos, such as extreme temperature variation $\left(-55\right.$ to $+70{ }^{\circ} \mathrm{C}$ for storage and -40 to $+5{ }^{\circ} \mathrm{C}$ for operation) and rapid diurnal cycles, low surface gravity (leading to difficulties in rover operation), dust (potentially contaminating optics and actuator mechanism), vacuum (complicating the heat distribution within the instrument), and radiation (potentially deteriorating the transmission of optics and electronics). Furthermore, the RAX instrument must be particularly small and lightweight to fit in the low-mass rover. An overview 
of the RAX instrument, its general specifications, current development status, and a design to overcome the abovementioned constraints are described in this section.

The RAX instrument consists of two physically separated units: the RAX laser assembly (RLA) and the RAX spectrometer module (RSM) (Fig. 3). The autofocusing subsystem (AFS), dedicated to focusing the laser on the surface of Phobos, is accommodated within the RSM. The entire RAX instrument has a volume of approximately $81 \times 125 \times 98 \mathrm{~mm}^{3}$ and a mass of approximately $1.4 \mathrm{~kg}$. The Institute of Optical Sensor Systems at DLR has developed the RSM. The University of Tokyo, JAXA, and Rikkyo University, Japan, are responsible for the development of AFS. The Instituto Nacional de Técnica Aeroespacial (INTA) and the University of Valladolid, Spain, who built the RLS laser unit for the ExoMars 2022 mission, provided the RLA (Fig. 3).

The RLA is a compact laser module that emits a 532$\mathrm{nm} \mathrm{CW}$ laser beam at a variable power of up to $35 \mathrm{~mW}$
(Fig. 4a). It is essentially a flight spare of the laser unit developed for the ExoMars2022 mission (Rull et al. 2017). The RLA (Ribes-Pleguezuelo et al. 2019) provides laser light to the RSM (Fig. 4b, c) through an optical fiber. The collimated laser beam is focused onto the surface of Phobos through the AFS, which comprises an entrance light-shuttle objective lens (LSO) and an actuator mechanism (Fig. 4d). The scattered light is collected and collimated by the entrance objective and sent to the spectrometer module. A series of optics, such as a dichroic mirror, collimator lenses, slit, transmission grating, Raman edge filter, and camera objective lenses, are mounted inside the RSM. The image of the slit is acquired using the 3D-plus CMOS sensor. The 2D image is integrated to form a $1 \mathrm{D}$ line spectrum. The electronic setup for controlling the laser and focus actuator is accommodated in the RSM. A focused laser beam is imperative to maximize the intensity of Raman signals emerging from the target surface below
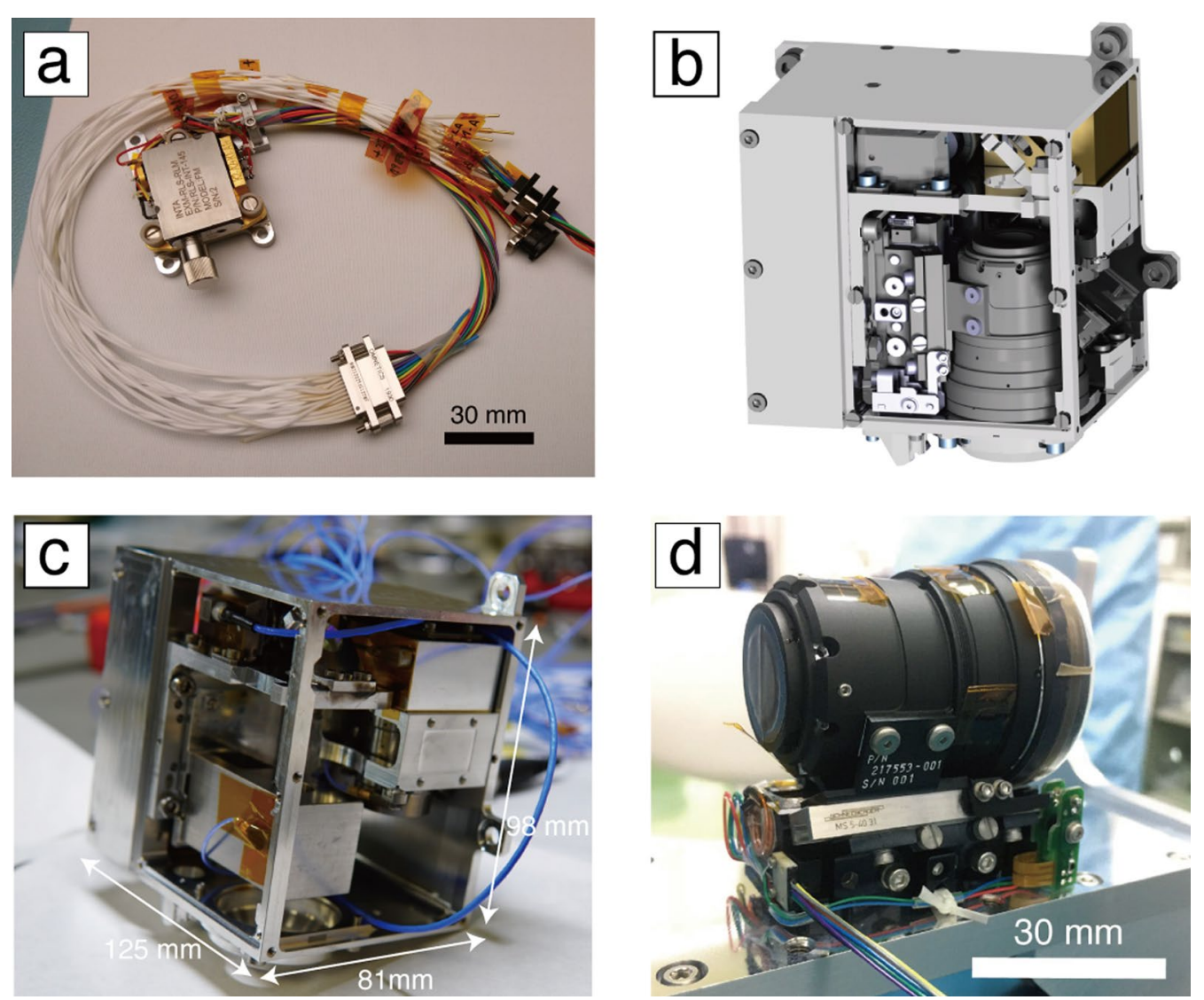

Fig. 4 a Engineering model of the RLA. Its mass is $112 \mathrm{~g}$ including the laser module, thermo-electrical module (TEM), interface plate, cables, and connectors. A new laser assembly batch, based on RLS (Ribes-Pleguezuelo et al. 2016) design, will be manufactured for the use in RAX (credit: RLS project). $\mathbf{b}$ CAD model of the RAX spectrometer module (RSM). AFS is observed in the frame. c Structural and thermal model (STM) being assembled at DLR. d AFS assembled in Japan. The LSO is placed on the linear translation mechanism. An end-stop sensor is placed between the two green printed circuit boards 
the rover, without damaging a possible heat-sensitive sample by laser irradiation (Rull et al. 2017). The laser spot diameter on the sample is designed to be $50 \mu \mathrm{m}$ to ensure a high Raman signal and no damage to the sample. The distance between the lowest tip of the LSO and the laser focus is $78 \mathrm{~mm}$. By design, the stroke of the LSO and its resolution are longer than $13 \mathrm{~mm}$ and finer than $<50 \mu \mathrm{m}$, respectively. Autonomous focusing involves a two-step procedure. In the first step, the reflectance spectra of surface materials, illuminated by the LED placed near the entrance aperture, are captured by focusing on the sample surface, using the rover legs and AFS actuator. The second step is fine focusing using the laser and only the AFS actuator, to maximize the signal-to-noise ratio (SNR) of the potential Raman signals. Furthermore, the backscattered laser light is measured by the RLA autofocus photodiode for accurate focus distance determination.

\section{Experimental setup}

To assess the capability of Raman spectroscopy using RAX, we built a breadboard model (BBM) using commercial components, which simulates the performance of the actual RAX instrument (Fig. 5). In this section, we describe the experimental setup of the proposed $\mathrm{BBM}$ in comparison with the RAX flight instrument.
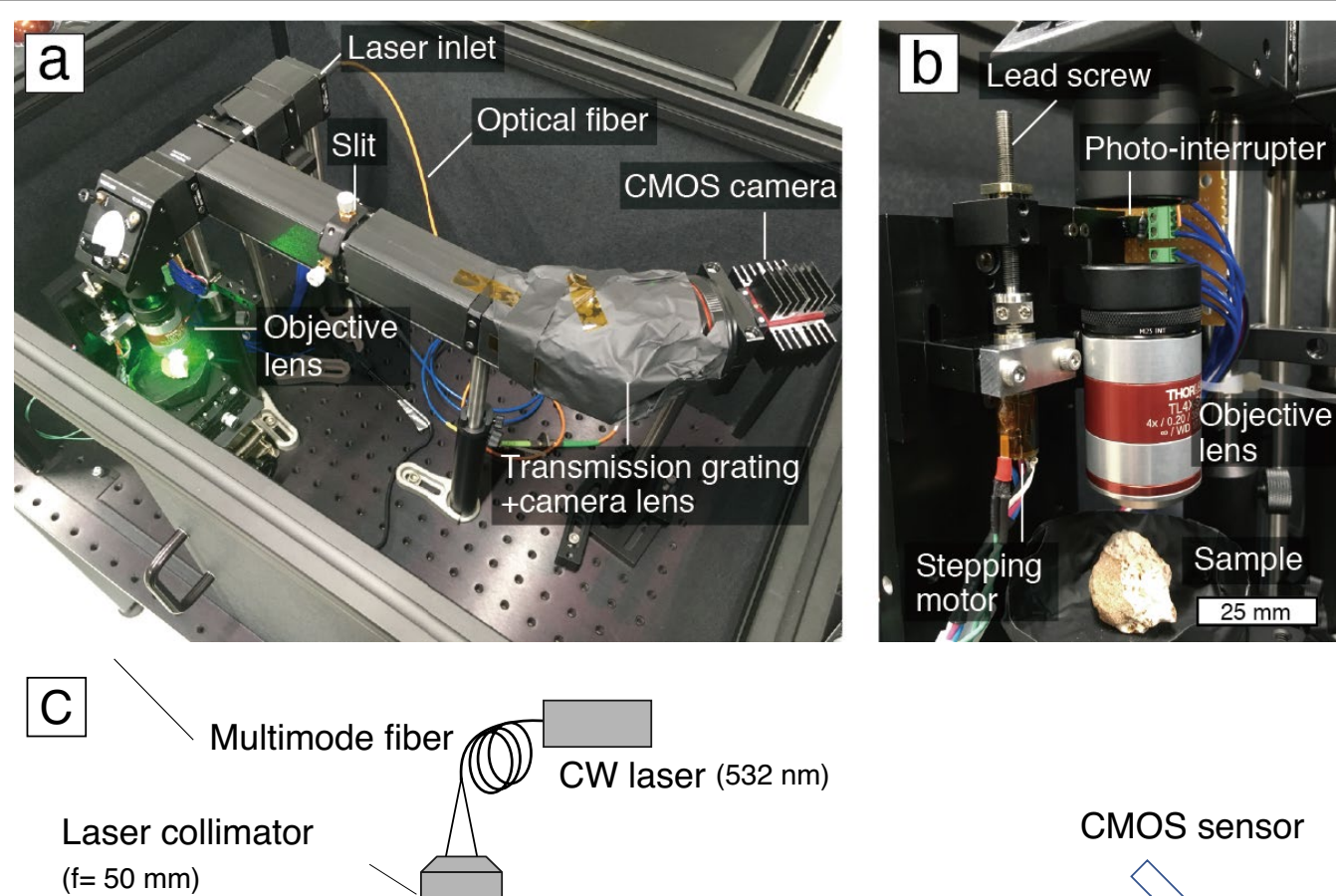

CMOS sensor $(\mathrm{f}=50 \mathrm{~mm})$

Laser cleaning filter

Dichroic beamsplitter

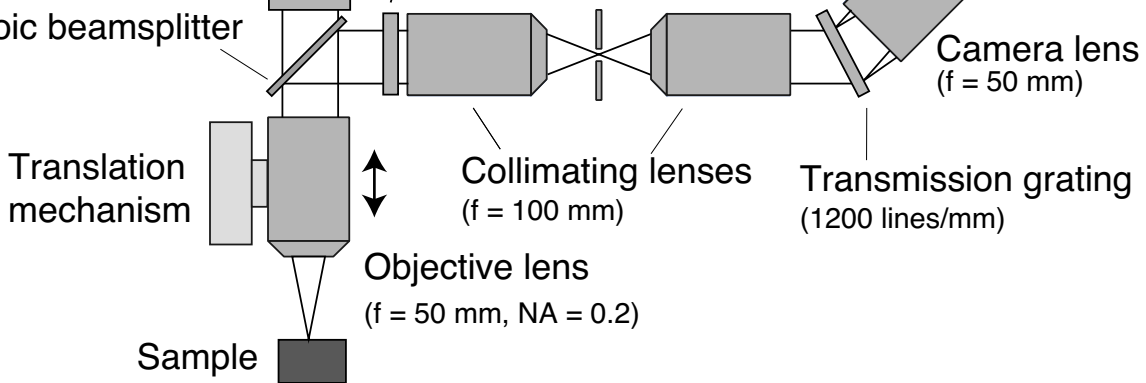

Fig. 5 BBM of RAX. a Entire breadboard. b Focusing unit. c Schematic diagram of BBM (see also Rodd-Routley et al. 2021). Actuator rotations are converted to vertical motion with a lead screw and linear guide. The actuator and linear guide are the COTS components used for the RAX flight model after screening. Mass of the lens is comparable to the flight lens barrel 


\section{Breadboard model}

We used a fiber-fed Nd:YAG laser that emits $\mathrm{CW}$ radiation at $532.2 \mathrm{~nm}$ (JUNO532FC, SOC, Japan). To simulate the output of the RLA, the power was set at $32 \mathrm{~mW}$, resulting in a laser irradiance of $1.6 \mathrm{~kW} / \mathrm{cm}^{2}$ at the target surface. The laser was connected to the BBM through a multimode optical fiber that simulates the non-Gaussian beam pattern for the flight laser. Similar to RAX, a spot size of $50 \mu \mathrm{m}$ was used. A laser clean-up filter, which transmits $>90 \%$ of the laser light at $532 \pm 1 \mathrm{~nm}$ while suppressing out-of-band photons with the optical density $(\mathrm{OD})>6$, was placed in the optical path.

To simulate the LSO performance in terms of light collection capability, the numerical aperture (NA) of the lens in our BBM was set at 0.20 , comparable to 0.22 of the actual RAX-LSO design (Rodd-Routley et al. 2021). As the stepping motor rotates, the lens moves vertically via the combination of a linear guide and a lead screw (Fig. 5). The stepping motor was identical to those of the RAX design. The objective lens had a mass of $143 \mathrm{~g}$, similar to that of RAX-LSO (129 g). Dedicated motor control electronics were manufactured and used to verify the electrical behavior of the motor. The resolution of the vertical motion that can be activated by one motor pulse, was measured to be $<25 \mu \mathrm{m}$.

To prevent the intense Rayleigh light $(532 \mathrm{~nm})$ from saturating the detector, a dichroic beam splitter (DBS) and an edge laser quelling filter (LQF) were inserted in the optical path. The DBS passes $>93 \%$ of the laser light at $<534 \mathrm{~nm}$, while reflecting the light with the Raman shift of the longer wavelengths toward the spectrometer module. The long-pass edge filter further cuts off the Rayleigh light by orders of magnitude (OD>6 at $532 \mathrm{~nm}$ ), but it passes $>93 \%$ of Raman-scattered photons at $>535.4 \mathrm{~nm}$ $\left(>117 \mathrm{~cm}^{-1}\right)$. Because of these mirrors and filters, the Raman spectra were measured only at Raman shifts higher than $100 \mathrm{~cm}^{-1}$. The sensitivity to low wavenumber Raman peaks will be evaluated with the engineering model of RAX, using a flight-like filter and beam splitter.

The Raman-scattered light was cut by a $50-\mu \mathrm{m}$ slit between the collimator lenses $(f=100 \mathrm{~mm})$. The collimated light passed a transmission grating (1200 grooves/ $\mathrm{mm})$. A camera lens $(f=50 \mathrm{~mm})$ was connected to the commercial off-the-shelf (COTS) CMOS camera with a custom-made flange, thus projecting the slit images of different wavelengths onto the CMOS sensor. Because of the magnification of the optical system in our BBM, the slit width was imaged at $25 \mu \mathrm{m}$ on the sensor, the same image size as that of the RAX design. The detector of the COTS CMOS camera was same as that of the 3D-plus flight CMOS sensor. The monochromatic sensor had a resolution of $2048 \times 2048$ pixels with an individual pixel size of $5.5 \mu \mathrm{m}$. Active cooling was not applied in the experiment.

\section{Measurement protocol}

Using this BBM, relevant bulk natural mineral samples were selected and measured, namely anhydrous rockforming minerals (olivine and quartz), carbonates (calcite and magnesite), sulfate (gypsum), and magnesium hydroxide (brucite). Once a sample is placed in the sample holder, the objective lens is focused by the actuator motion. In this study, the focus was manually adjusted using a motor control software to maximize the intensity of the Raman signals. The measurements were conducted in air at room temperature.

The entire BBM was placed in an optical enclosure to avoid ambient light entering the system through the objective lens. Furthermore, the optical path was covered by black plastic or anodized aluminum to prevent strong Rayleigh light from entering the optical path. The relationship between the CMOS sensor pixels and Raman shift $\left(\mathrm{cm}^{-1}\right)$ was calibrated with a Ne lamp, using $34 \mathrm{Ne}$ emission lines from $534.3 \mathrm{~nm}\left(79 \mathrm{~cm}^{-1}\right)$ to $703.2 \mathrm{~nm}$ $\left(4575 \mathrm{~cm}^{-1}\right)$. The wavenumber-pixel relation was fitted with a third polynomial, and the root mean square error in wavenumber calibration was $0.95 \mathrm{~cm}^{-1}$. One pixel corresponded to $3-2 \mathrm{~cm}^{-1}$ in the $0-4000 \mathrm{~cm}^{-1}$ range. Among the 2048 vertical pixels of the CMOS sensor, 500 lines containing the spectral images were integrated to derive a spectrum. The exposure time of the Raman measurements was set to $1 \mathrm{~s}$ for each specimen. These short exposure times were selected to demonstrate that our instrument design allows for measurements of the Raman spectra of minerals expected on Phobos, even with a short integration time, which is the baseline operation mode on Phobos. One hundred spectra were averaged to enhance the SNR of the spectra. Background (dark) spectra were measured with the same exposure time and number of spectra averaged when the laser was turned off. The dark spectra were subtracted from the signal spectra to remove thermal noise. The relative spectral response of the system was corrected using a standard halogen lamp.

Each Raman peak was fitted with a Gaussian profile and the height $S$, width $W$, and position $C$ of each Gaussian fit were derived. The fluorescence continuum was fitted simultaneously and subtracted from the spectrum. The noise level $N$, associated with individual peaks, was defined by the standard deviation of the signals over 40 pixels in the continuum-subtracted spectra. The standard deviation was measured across the spectral band of 20 pixels (approximately $60 \mathrm{~cm}^{-1}$ ) on each side of the peak, at a distance of 3 times peak width $W$ from the Raman 
feature peak. The SNR was calculated by dividing the peak signal $S$ by the noise level $N$.

\section{Results and discussion}

The Raman spectra obtained with our RAX BBM are shown in this section to verify the detectability of the minerals using the RAX instrument. Figure 6 shows the Raman spectra of the minerals measured using the BBM. The double peaks, characteristic of olivine, at $823 \mathrm{~cm}^{-1}$ and $854 \mathrm{~cm}^{-1}$ were clearly detected and resolved with our BBM. The peak positions are consistent with those of olivine of $\mathrm{Mg} \#=90$ (Kuebler et al. 2006), demonstrating that the RAX instrument can determine the solid solution composition of olivine. The Raman spectrum of quartz shows a peak attributable to the $\mathrm{Si}-\mathrm{O}-\mathrm{Si}$ vibration mode at $464 \mathrm{~cm}^{-1}$ (Fig. 6). For quartz, the peak was detected at $129 \mathrm{~cm}^{-1}$, which indicates the smallest Raman shift observed in this study. No sharp peaks due to cosmic rays were observed in the averaged spectra.

Figure 6 also shows the Raman spectra of the two carbonates: calcite $\left(\mathrm{CaCO}_{3}\right)$ and magnesite $\left(\mathrm{MgCO}_{3}\right)$, both yielding unambiguous Raman peaks above the continuum due to fluorescence. OH-related bands at wavenumbers $>3000 \mathrm{~cm}^{-1}$ were observed for gypsum $\left(\mathrm{CaSO}_{4} \cdot 2 \mathrm{H}_{2} \mathrm{O}\right)$ and brucite $\left(\mathrm{Mg}(\mathrm{OH})_{2}\right)$. The Raman peaks of gypsum, at 3401 and $3491 \mathrm{~cm}^{-1}$, were characteristic

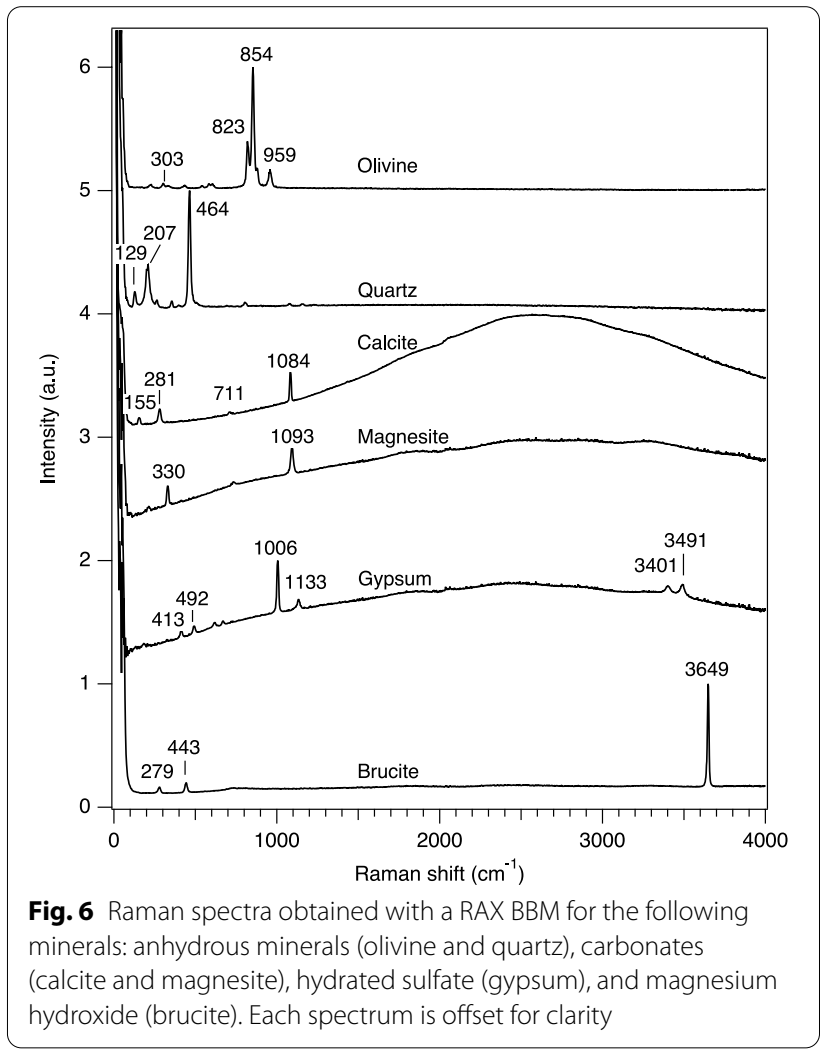

of water, while brucite exhibits an $\mathrm{OH}$ vibration mode at $3649 \mathrm{~cm}^{-1}$ (Fig. 6). The SNR of the individual peaks achieved using our BBM are summarized in Table 2 . The SNRs achieved in this study ranged from several to 100 . The grain size, mineral mixtures, and surface roughness can influence the intensity of specific Raman spectra (Foucher et al. 2013; Böttger et al. 2017). These aspects will be characterized in further investigations with a focus on the expected Phobos mineralogy. Nevertheless, our data suggest that a very compact Raman spectrometer such as the RAX instrument can be used for in situ detection of minerals expected on Phobos.

\section{Conclusion}

Raman spectroscopy is a suitable technique for in situ analysis of the mineralogy of Phobos and determination of the origin of Phobos. RAX is a very compact and robust instrument being developed for the rover of the MMX mission to Phobos. In this study, we showed the main design of the instrument, particularly with respect to the challenges associated with a mission to Phobos, and the size/mass constraints of the small MMX rover. The first results of Raman measurements of Phobos-relevant minerals using a BBM of similar performance, as expected for the flight model, show that RAX will be able

Table 2 Identified Raman peaks and their SNRs

\begin{tabular}{|c|c|c|c|}
\hline Sample & Sample type & $\begin{array}{l}\text { Peak position } \\
\left(\mathrm{cm}^{-1}\right)\end{array}$ & $\begin{array}{l}\text { Signal-to- } \\
\text { noise ratio }\end{array}$ \\
\hline \multirow[t]{4}{*}{ Olivine } & Crystalized bulk & 303 & 6 \\
\hline & & 823 & 21 \\
\hline & & 854 & 55 \\
\hline & & 959 & 48 \\
\hline \multirow[t]{3}{*}{ Quartz } & Bulk & 129 & 12 \\
\hline & & 207 & 19 \\
\hline & & 464 & 54 \\
\hline \multirow[t]{4}{*}{ Calcite } & Bulk & 155 & 8 \\
\hline & & 281 & 27 \\
\hline & & 711 & 8 \\
\hline & & 1084 & 99 \\
\hline \multirow[t]{2}{*}{ Magnesite } & Bulk & 330 & 32 \\
\hline & & 1093 & 54 \\
\hline \multirow[t]{6}{*}{ Gypsum } & Bulk & 413 & 5 \\
\hline & & 492 & 6 \\
\hline & & 1006 & 80 \\
\hline & & 1133 & 14 \\
\hline & & 3401 & 21 \\
\hline & & 3491 & 19 \\
\hline \multirow[t]{3}{*}{ Brucite } & Bulk & 279 & 38 \\
\hline & & 443 & 67 \\
\hline & & 3649 & 61 \\
\hline
\end{tabular}


to resolve the olivine doublet at approximately 820 and $850 \mathrm{~cm}^{-1}$, and carry out highly sensitive measurements to identify the minerals. Our results indicate that RAX will be able to obtain the Raman spectra of key minerals potentially distributed on Phobos.

\begin{abstract}
Abbreviations
AFS: Autofocusing subsystem; BBM: Breadboard model; CAD: Computeraided design; CMOS: Complementary metal oxide semiconductor; COTS: Commercial off-the-shelf; CW: Continuous wave; DLR: Deutsches Zentrum für Luft- und Raumfahrt; EM: Engineering model; FM: Flight model; INTA: Instituto Nacional de Técnica Aeroespacial; JAXA: Japan Aerospace Exploration Agency; LED: Light emitting diode; LSO: Light shuttle objective; MMX: Martian Moons eXploration; Nd:YAG: Neodymium-doped yttrium aluminum garnet; RAX: Raman spectrometer for MMX; RLA: RAX laser assembly; RSM: RAX spectrometer module; SEM: Secondary electron microscope; SNR: Signal-to-noise ratio; STM: Structural and thermal model.
\end{abstract}

\section{Acknowledgements}

The authors thank two anonymous reviewers for their constructive review that helped us improve the paper. The olivine sample was provided by Dr. Shogo Tachibana of the University of Tokyo. The Raman spectra presented in Figs. 1 and 2 are measured at the Raman laboratory of the DLR-Institute for Planetary Research in Berlin, Germany.

\section{Authors' contributions}

$Y C$ wrote the paper, with contributions from $U B, F R, H W H, A M I, G L R, J A O$, and IW. Conception, design, and revision of the work: YC, UB, HWH, FR, MB, SK, SRR, PS, SU, and TU. Conception of the instrument: UB, HWH, AB, ED, TH, CR, SRR and FS. Data acquisition and analysis: YC, SM, JAO, MP, SR, TS, SS, KY. Interpretation of the data: $Y C, U B, F R, M P, S R$, TS, and IW. TB, AB, ED, TH, MP, GP, CR, SRR, and $F S$ designed the instrument. $Y C, E D, S M, G P$, and $K Y$ built the instrument. $Y B, S M, K W, K Y$ created the software used in this study. The concept of the autofocusing algorithm was developed by TS. EK developed the new electronics used in this study. ML, SR, and CR created the new structure models and analyzed their data. New detector models were developed by CP. AMI, CCP, and PRP contributed to the conception and design of the laser. SS and TS led the discussion on the concept of operation. The discussion on the science of in situ Raman spectroscopy was led by GLR, OPB, CS, and IW. MB was in charge of project management. All authors read and approved the final manuscript.

\section{Funding}

This study was supported by Japan Society for Promotion of Science Grant-in-Aid (Grant numbers JP19K14778 and JP20H04607). From the Spanish side the project is partially funded by the MINECO Project Reference PID2019-107442RB-C3 and PID2019-107442RB-C2.

\section{Availability of data and materials}

The datasets used and/or analyzed during the current study are available from the corresponding author on reasonable request.

\section{Declarations}

Ethics approval and consent to participate

Not applicable.

\section{Consent for publication}

Not applicable.

\section{Competing interests}

The authors declare that they have no competing interests.

\section{Author details}

${ }^{1}$ Department of Earth and Planetary Science, The University of Tokyo, 7-3-1 Hongo, Bunkyo, Tokyo 113-0033, Japan. ${ }^{2}$ Institute of Optical Sensor Systems, Deutsches Zentrum für Luft- und Raumfahrt e.V. (DLR), Rutherfordstr. 2, 12489 Berlin, Germany. ${ }^{3}$ Universidad de Valladolid - GIR ERICA, Av. Francisco valles, 8, Parque Tecnólogico de Boecillo, Parcela 203, 47151 Boecillo, Valladolid, Spain. ${ }^{4}$ Instituto Nacional de Técnica Aerospacial (INTA), Ctra. Ajalvir, Km 4, 28850 Torrejón de Ardoz, Spain. ${ }^{5}$ Department of Physics, College of Science, Rikkyo University, 3-34-1 Nishiikebukuro, Toshima, Tokyo 171-8501, Japan. ${ }^{6}$ Centro de Astrobiología (CAB-INTA-CSIC), Ctra. Ajalvir, Km 4, 28850 Torrejón de Ardoz, Spain. Institute for Planetary Research, Deutsches Zentrum für Luft- und Raumfahrt e.V. (DLR), Rutherfordstr. 2, 12489 Berlin, Germany. ${ }^{8}$ Space Operations and Astronaut Training, Deutsches Zentrum für Luft- und Raumfahrt e.V. (DLR), Linder Höhe, 51147 Cologne, Germany. ${ }^{9}$ Institute of Space and Astronautical Science, Japan Aerospace Exploration Agency (JAXA), 3-1-1 Yoshinodai, Chuo, Sagamihara, Kanagawa 252-5210, Japan. ${ }^{10}$ Institut für Planetologie, WWU Münster, Wilhelm-Klemm-Str. 10, 48149 Münster, Germany,

Received: 15 January 2021 Accepted: 11 August 2021

Published online: 19 December 2021

\section{References}

Ballouz RL, Baresi N, Crites ST, Kawakatsu Y, Fujimoto M (2019) Surface refreshing of Martian moon Phobos by orbital eccentricity-driven grain motion. Nat Geosci 12:229-234. https://doi.org/10.1038/s41561-019-0323-9

Böttger U, Alwmark C, Bajt S, Busemann H, Gilmour JD, Heitmann U, Hübers H-W, Meier MMM, Pavlov SG, Schade U, Spring NH and Weber I (2013) Raman Micro-spectroscopy of HAYABUSA particles. In: HAYABUSA 2013 symposium of solar systems materials, Tokyo, 16-18 October 2013

Böttger U, Pavlov SG, Deßmann N, Hanke F, Weber I, Fritz J, Hübers H-W (2017) Laser-induced alteration of Raman spectra for micron-sized solid particles. Planet Space Sci 138:25-32. https://doi.org/10.1016/j.pss.2017.02.001

Busemann H, Alwmark C, Bajt S, Böttger U, Gilmour JD, Heitmann U, Hübers H-W, Meier MMM, Pavlov S, Schade U, Spring NH, Weber I (2013) Asteroid Itokawa studied by micro-raman and infrared spectroscopy, X-ray tomography and high-sensitivity noble gas analysis. In: HAYABUSA 2013 symposium of solar systems materials, Tokyo, 16-18 October 2013

Ebihara M, Sekimoto S, Shirai N, Hamajima Y, Yamamoto M, Kumagai K, Oura Y, Ireland TR, Kitajima F, Nagao K, Nakamura T, Naraoka H, Noguchi T, Okazaki R, Tsuchiyama A, Uesugi M, Yurimoto H, Zolensky ME, Abe M, Fujimura A, Mukai T, Yada Y (2011) Neutron activation analysis of a particle returned from asteroid Itokawa. Science 333:1119. https://doi.org/10. 1126/science. 1207865

Foucher F, Lopez-Reyes G, Bost N, Rull-Perez F, Rüßmann P, Westall F (2013) Effect of grain size distribution on Raman analyses and the consequences for in situ planetary missions. J Raman Spectrosc 44(6):916-925

Hagelschuer T, Belenguer T, Böttger U, Buder M, Cho Y, Dietz E, Gensch M, Hanke F, Hübers H-W, Kameda S, Kopp E, Kubitza S, Moral A, Paproth C, Pertenais M, Peter G, Rammelkamp K, Rodriguez P, Rull F, Ryan C, Säuberlich T, Schrandt F, Schröder S, Ulamec S, Usui T, Vance R (2019) The Raman spectrometer onboard the MMX rover for Phobos. In: Proceedings of the 70th international astronautical congress (IAC), Walter E. Washington Convention Center, 21-25 October 2019

Hyodo R, Kurosawa K, Genda Y, Usui T, Fujita K (2019) Transport of impact ejecta from Mars to its moons as a means to reveal Martian history. Sci Rep 9:19833. https://doi.org/10.1038/s41598-019-56139-x

Kawakatsu Y, Kuramoto K, Ogawa N, Ikeda H, Ono G, et al. (2019) Mission definition of martian moon exploration (MMX). In: 70th international astronautical congress (IAC), Walter E. Washington Convention Center, 21-25 October 2019

Krot A (2011) Bringing part of an asteroid back home. Science 333:1098. https://doi.org/10.1126/science.1212145

Kuebler K, Jolliff BL, Wang A, Haskin LA (2006) Extracting olivine (Fo-Fa) composition from Raman spectral peak positions. Geochim Cosmochim Acta 70:6201-6222. https://doi.org/10.1016/j.gca.2006.07.035

Kuramoto K et al (2021) Martian moons exploration MMX: sample return mission to Phobos elucidating formation processes of habitable planets. Earth Planets Space. https://doi.org/10.1186/s40623-021-01545-7

Meier MMM, Alwmark C, Bajt S, Böttger U, Busemann H, Gilmour J, Heitmann U, Hübers H-W, Marone F, Pavlov S, Schade U, Spring NH, Stampanoni M, Terfelt F, Weber I (2013) Determining a precise HE, NE cosmic-ray exposure age for grains from Itokawa. In: HAYABUSA 2013 symposium of solar systems materials, Tokyo, 16-18 October 2013 
Michel P et al (2021) The MMX rover: performing in-situ surface investigations on Phobos. Earth Planets Space. https://doi.org/10.1186/ s40623-021-01464-7

Murchie SL, Britt DT, Pieters CM (2014) The value of Phobos sample return. Planet Space Sci 102:176-182. https://doi.org/10.1016/j.pss.2014.04.014

Nagao K, Okazaki R, Nakamura T, Miura YN, Osawa T, Ki B, Matsuda S, Ebihara M, Ireland TR, Kitajima F, Naraoka H, Noguchi T, Tsuchiyama A, Yurimoto H, Zolensky ME, Uesugi M, Shirai K, Abe M, Yada T, Ishibashi Y, Akio Fujimura A, Mukai T, Ueno M, Okada T, Yoshikawa M, Kawaguchi J (2011) Irradiation history of Itokawa regolith material deduced from noble gases in the Hayabusa samples. Science 333:1128. https://doi.org/10.1126/science. 1207785

Nakamura T, Noguchi T, Tanaka M, Zolensky ME, Kimura M, Tsuchiyama A, Nakato A, Ogami T, Ishida H, Uesugi M, Yada T, Shirai K, Fujimura A, Okazaki R, Sandford SA, Ishibashi Y, Abe M, Okada T, Ueno M, Mukai T, Yoshikawa M, Kawaguchi J (2011) Itokawa dust particles: a direct link between S-type asteroids and ordinary chondrites. Science 333:1113. https://doi. org/10.1126/science.1207758

Pieters CM, Murchie S, Thomas N, Britt D (2014) Composition of surface materials on the moons of Mars. Planet Space Sci 102:144-151. https://doi.org/ 10.1016/j.pss.2014.02.008

Ramsley KR, Head JW (2013) Mars impact ejecta in the regolith of Phobos: bulk concentration and distribution. Planet Space Sci 87:115-129. https://doi. org/10.1016/j.pss.2013.09.005

Ribes-Pleguezuelo P, Inza AM, Basset MG, Rodríguez P, Rodríguez G, Laudisio M, Galan M, Hornaff M, Beckert E, Eberhardt R, Tünnermann A (2016) Assembly processes comparison for a miniaturized laser used for the Exomars European Space Agency mission. Opt Eng 55(11):116107. https://doi.org/10.1117/1.OE.55.11.116107

Ribes-Pleguezuelo P, Guiloht D, Basset MG, Beckert E, Eberhardt R, Tünnermann A (2019) Insights of the qualified ExoMars laser and mechanical considerations of its assembly process. Instruments 3:25. https://doi.org/ 10.3390/instruments3020025

Rodd-Routley S, Belenguer T, Böttger U, Buder M, Cho Y, Dietz E, Hagelschuer T, Hübers H-W, Kameda S, Kopp E, Moral Inza AG, Prieto-Ballesteros O, Rockstein S, Rull F, Ryan C, Säuberlich T, Schrandt F, Usui T, Yumoto K (2021) Optical design and breadboard of the Raman spectrometer for MMX-RAX, LPSC 52 Abstract 1923

Rosenblatt P (2011) The origin of the Martian moons revisited. Astron Astrophys Rev 19:44. https://doi.org/10.1007/s00159-011-0044-6

Rull F, Maurice S, Hutchinson I, Moral A, Perez C, Diaz C, Colombo M, Belenguer T, Lopez-Reyes G, Sansano A, Forni O, Parot Y, Striebig N, Woodward S, Howe C, Tarcea N, Rodriguez P, Seoane L, Santiago A, Rodriguez-Prieto JA, Medina J, Gallego P, Canchal R, Santamarı'a P, Ramos G, Vago JL, RLS Team (2017) The Raman laser spectrometer for the ExoMars rover mission to Mars. Astrobiology 17(6-7):627. https://doi.org/10.1089/ast.2016.1567

Shirley K, Glotch T (2018) Effects of visible albedo on mid-infrared spectra under simulated lunar environment as compared to diviner lunar radiometer. In: European Planetary Science Congress (EPSC) 2018, Technische Universität (TU) Berlin, 16-21 September 2018

Ulamec S, Michel P, Grott M, Böttger U, Hübers H-W, Murdoch N, Vernazza P, Karatekin Ö, Knollenberg J, Willner K, Grebenstein M, Mary S, Chazalnoël P, Biele J, Krause C, Ho T-M, Lange C, Grundmann J-T, Sasaki K, Maibaum M, Küchemann O, Reill J, Chalon M, Barthelmes S, Lichtenheldt R, Krenn R, Smisek M, Bertrand J, Moussi A, Delmas C, Tardivel S, Arrat D, ljpelaan F, Mélac L, Lorda L, Remetean E, Lange M, Mierheim O, Reershemius S, Usui T, Matsuoka M, Nakamura T, Wada K, Miyamoto H, Kuramoto K, LeMaitre J, Mas G, Delpech M, Celine L, Rafflegeau A, Boirard H, Schmisser R, Virmontois C, Cenac-Morthe C, Besson D, Rull F (2019) A rover for the MMX mission to Phobos. In: 70th International Astronautical Congress, (IAC), Walter E. Washington Convention Center, 21-25 October 2019

Usui T, Bajo K, Fujiya W, Furukawa Y, Koike M, Miura YN, Sugahara H, Tachibana S, Takano Y, Kuramoto K (2020) The importance of Phobos sample return for understanding the Mars-Moon system. Space Sci Rev 216:49. https:// doi.org/10.1007/s11214-020-00668-9

Weber I, Böttger U, Pavlov SG, Hübers H-W, Hiesinger H, Jessberger EK (2017) Laser alteration on iron sulfides under various environmental conditions. J Raman Spectrosc 48(11):1509-1517. https://doi.org/10.1002/jrs.5083

Weber I, Böttger U, Pavlov SG, Stojic A, Hübers H-W, Jessberger EK (2018) Raman spectra of hydrous minerals investigated under various environmental conditions in preparation for planetary space missions. $J$ Raman Spectrosc 49(11):1830-1839. https://doi.org/10.1002/jrs.5463 Wiens RC, Maurice S, Robinson SH, Nelson AE, Cais P, Bernardi P, Newell RT, Clegg S, Sharma SK, Storms S, Deming J, Beckman D, Ollila AN, Gasnault O, Anderson RB, Andre Y, Angel SM, Arana G, Auden E, Beck P, Becker J, Benzerara K, Bernard S, Beyssac O, Borges L, Bousquet B, Boyd K, Caffrey M, Carlson J, Castro K, Celis J, Chide B, Clark K, Cloutis E, Cordoba EC, Cousin A, Dale M, Deflores L, Delapp D, Deleuze M, Dirmyer M, Donny C, Dromart G, Duran MG, Egan M, Ervin J, Fabre C, Fau A, Fischer W, Forni O, Fouchet T, Fresquez R, Frydenvang J, Gasway D, Gontijo I, Grotzinger J, Jacob X, Jacquinod S, Johnson JR, Klisiewicz RA, Lake J, Lanza N, Laserna J, Lasue J, Mouélic SL, Legett C, Leveille R, Lewin E, Lopez-Reyes G, Lorenz R, Lorigny E, Love SP, Lucero B, Madariaga JM, Madsen M, Madsen S, Mangold N, Manrique JA, Martinez JP, Martinez-Frias J, McCabe KP, McConnochie TH, McGlown JM, McLennan SM, Melikechi N, Meslin P-Y, Michel JM, Mimoun D, Misra A, Montagnac G, Montmessin F, Mousset V, Murdoch N, Newsom H, Ott LA, Ousnamer ZR, Pares L, Parot Y, Pawluczyk R, Peterson CG, Pilleri P, Pine P, Pont G, Poulet F, Provost C, Quertier B, Quinn H, Rapin W, Reess J-M, Regan AH, Reyes-Newell AL, Romano PJ, Royer C, Rull F, Sandoval B, Sarrao JH, Sautter V, Schoppers MJ, Schröder S, Seitz D, Shepherd T, Sobron P, Dubois B, Sridhar V, Toplis MJ, Torre-Fdez I, Trettel IA, Underwood M, Valdez A, Valdez J, Venhaus D, Willis P (2021) The SuperCam instrument suite on the NASA Mars 2020 rover: body unit and combined system tests. Space Sci Rev 217:4. https://doi.org/10.1007/ s11214-020-00777-5

Yurimoto H, Ki A, Abe M, Ebihara M, Fujimura A, Hashiguchi M, Hashizume K, Ireland TR, Itoh S, Katayama J, Kato C, Kawaguchi J, Kawasaki N, Kitajima F, Kobayashi S, Meike T, Mukai T, Nagao K, Nakamura T, Naraoka H, Noguchi T, Okazaki R, Park C, Sakamoto N, Seto Y, Takei M, Tsuchiyama A, Uesugi M, Wakaki S, Yada T, Yamamoto K, Yoshikawa M, Zolensky ME (2011) Oxygen isotopic compositions of asteroidal materials returned from Itokawa by the Hayabusa mission. Science 333:1116. https://doi.org/10.1126/scien ce. 1207776

\section{Publisher's Note}

Springer Nature remains neutral with regard to jurisdictional claims in published maps and institutional affiliations.

\section{Submit your manuscript to a SpringerOpen ${ }^{\circ}$ journal and benefit from:}

- Convenient online submission

- Rigorous peer review

- Open access: articles freely available online

- High visibility within the field

- Retaining the copyright to your article

Submit your next manuscript at springeropen.com 